Article

\title{
Exploring the role of Biradari in career growth: Evidence from public sector organizations of Islamabad
}

\author{
Noreen Saher ${ }^{1}$, Tasmia Matloob ${ }^{2}$, Malik Shahzad Shabbir ${ }^{3 *}$ \\ 1 Department of Anthropology, International Islamic University, Islamabad, Pakistan; \\ noreen.saher@iiu.edu.pk \\ 2 Department of Sociology, Mirpur University of Science and Technology, Pakistan, tasmia.soc@must.edu.pk \\ 3 University of Lahore, Pakistan; mshahzad786.pk11@gmail.com \\ * Correspondence: mshahzad786.pk11@gmail.com
}

Received: 11 January 2020; Accepted: 5 May 2020; Published: 10 May 2020.

\begin{abstract}
Biradari (Brotherhood) is one of the most important principles of Pakistani culture. The Biradari ties are considered very strong among south Asian communities, especially in Pakistan. It is an important cultural element of Punjabi cultural setup, considered as the strong binder in making group alliances and performs a significant role in daily life. The major objective of this research is to study the crucial role of Biradari relations in organizations and how does it affect the career growth of an individual. Academic researchers have highlighted different indicators and factors which contribute to career growth. Social networks, sifarish, and favoritism are deeply embedded dimensions of Pakistani culture. This research significantly contributes to the literature by giving the holistic view of Biradari and the importance of Biradari based networks in job selection and promotion. The research is conducted in the public sector organization of Islamabad (PIMS). The qualitative research methodology was used for this study and data was collected from fifteen (15) employees through in-depth interviews. The results of the study reveal that Biradari significantly influences the career growth of individual and it is considered as strong support for individual career growth. The results have further highlighted that in today's competitive environment individuals cannot able to achieve a successful career without using his/her networks.
\end{abstract}

Keywords: Biradari; Networking; Social Capital; Career Growth; Pakistan

JEL Classification: I13, I15, I28

\section{Introduction}

The cultural elements of Biradari and Vartan Bhanji operate and govern social relationships within the economic and political organizations in contemporary Pakistan (Lyon, 2002; Qadeer, 2006; Saher \& Mayrhofer, 2014; Nasir \& Mielke 2015). Researchers using social networking and capital theories have highlighted the significance of cultural practices of reciprocity for creating networks within and outside of the organizations wherein, individuals who have close links with different networks easily get desired benefits. In the context of Pakistan, Biraderi, as well as Vartan Bhanji, plays a vital role to develop more, networks, cohesion, affiliations, and support at social, economic, and political levels. Using familial ties and Biraderi relations (based on Paki Vartan or courtesy relations (katchi Vartan) are significant in creating alliances among members of the same groups. These cultural mechanisms (usually based on reciprocity) are utilized as an effective approach to creating a network of relationships that ultimately help individuals to support their official affairs within the 
organizations. We can recognize the reflection of Vartan Bhanji (indigenous societal pattern of Pakistani society) operate in modern human resource management practices where the traditional mechanism of VB is used as a strategy to attain specific favors and objectives among the members of the organizations (Saher, 2010; Saher \& Mayrhofer, 2014).

Peter M, Blau has comprehensively discussed how dynamic relations are emerged at individual and group levels when people jointly pursue their interests. According to Blau, these reciprocal relations/processes are established and maintained through a culturally and morally legitimate value system that creates integration and social solidarity among people of wider society. Depending on the nature of interaction/relations, these processes further lead to exchange relations which may be rewarding for individuals (Blau, 1964:24). We argue that as principle values of the cultural system of Pakistan, relations based on Biraderi and Vartan Bhanji significantly influence individuals' interaction, activities, and expectations both at personal and professional levels. This reciprocity (Vartan Bhanji) is expressed through various ways in Pakistani culture; generally, it is expressed through the exchange of gifts which is taken as an expression of solidarity between kin and non-kins (Shaw, 2000). Our point of view is that these reciprocal obligations play a key role to assert social and moral pressure in public/official affairs between the members who maintain strong VB and extended familial relations. It serves as a symbolic means to assert the pressure of Biraderi and VB based relations where ignoring a request is considered as unethical, which has its social significance for affective relationships within groups/biradari. This pressure is asserted by giving expensive gifts and involving highly influential members from the same Biradari/group. Generally, it the framework of birders under the exchange mechanism of Vartan Bhanji which is maintained through the reciprocity of gifts/services and plays an essential role to maintain in-group and out-group relations within the organizations. This mechanism is used to enlarge the network of different groups and to enrich social capital. Thus, biradari operate as a vital gadget by establishing and maintaining social connections with a wider web of people that increases the probability of securing higher returns/benefits (Burt, 2000). Therefore, for creating a network of alliances for support, cultural values of reciprocity play an essential role at individual and organizational levels.

The main objective of this paper is to explore and develop an understanding of the mechanism of Biraderi and VB and how it works in organizational settings in Pakistan. This paper also highlights the ways these practices based on the principles of reciprocity, are used for successful organizational favors and support. This paper provides a precise understanding of how Biraderi and $\mathrm{Vb}$ are used as a mechanism exclusively to maximize and maintain personal/group interests. Furthermore, how Biraderi relations are used to create and maintain networks, consequently, enhance individual and group social capital at organizational levels.

\section{Literature Review}

\subsection{Defining the cultural mechanism of Biraderi}

First, it is necessary to understand the nature of the social patterns of Biraderi and VB. It will make easier to comprehend how these are implemented in official dealings in Pakistan. Biradari (Brotherhood) is the dominant force in the social and political system of Pakistan. It is an important cultural element of Punjabi cultural setup, considered as a strong binder in making group alliances and performs a significant role in daily life. According to Eagler (1960:90) "Biraderi is a patrilineage. All the men who can trace their relationship to a common ancestor, no matter how remote, belong to the same biraderi". Alavi states that biraderi is a group of people connected based on having the same ancestor. It includes all the households who consider themselves as originally belong to a common ancestor. Thus, it makes difficult to determine a particular limit or size of biraderi (Alavi, 1972: 2). However, Alavi's distinction is helpful to have a better understanding of the nature and scope of Biraderi relations. According to Alavi, the Biraderi relationships based on kinship are always comprised of families, organized on patrilineage relations through endogenous kinship units. However, biraderi relations based on non-kinship terms can be further recognized on two different layers of associations. 
First, 'biraderi of recognition', where relationships are determined through members links to the common descent. Second, 'biradari of participation', which is an involvement of the households (linked through biradari of recognition) in ritualistic reciprocal relations through the exchange of gifts (Alavi, 1972).

However, this kinship (biraderi) relations are also extended to other external members (non-kin) in particular situations which are significant to have smooth transactions with diverse groups. The mechanism of Vartan Bhanji is employed to extend relationships with others. VB is maintained among family/kin-members (biradari members) as well as with non-kin relations based on mutual trust and cooperation to maintain social networks within the organizations (Khilji, 2003: Saher \& Mayrhofer, 2014) where individuals get benefits based on their belonging to particular social groups. Extending kinship relationships with other close members or groups make it difficult to draw a clear line at where biradari relations end. Primarily, it is the nature, degree, obligations, and frequency to which VB is practiced in Biraderi relations (recognition, participation) is important. For this reason, sometimes friends, close neighbors, and other distant consanguine are incorporated into Biradari relations due to their frequent exchanges of services Shabbir (2019). The people included in this category also known as fraternal biradari (Darr, 1997). Individuals may be connected through the web of overlapping relations (biraderi and fraternal biraderi relations) with each other in particular organizational settings. Therefore, the term Biradari relations represent large web interdependent relations, exist within the different internal subgroups of Biraderi (based on recognition and participation). Biraderi integration is maintained at all levels through the cultural mechanism of social exchange (Vartan Bhanji) and it regulates the flow of services among the members.

According to Nahapiet \& Ghosal (1998), these networks based on the fabric of social relations provides a mutually owned capital to the members having shared acquaintances. Furthermore, these relations within organizations can be mobilized to pursue certain benefits. (Adler \& Known. 2002). This mutual reciprocation based on social relations is highly important within the organizational settings because it involves a series of relations between individuals and groups that result in obligations (Blau, 1964; Emerson, 1976; Cropanzano and Mitchell, 2005; Balkin and Richebe, 2007). It is a crucial element in organizational relations and this practice has a very striking impact on workplace relationships. These relationships are also highly remarkable to bridge the structural holes that exist due to differentiation (vertical or horizontal) between individuals according to their positions within the organizations. According to Widen-Wulff \& Ginman (2004) and Nahapiet \& Ghoshal (1998) that patterns of relationships based on intensity, concentration, connectivity, and hierarchy are highly significant to form and utilize social capital. Social capital is the set of resources that inheres in the structure of relations between individual actors (Coleman, 1988, 1990; Burt, 1992, 2000) in which individuals or groups are linked with each other through reciprocity/exchange of services.

The reciprocity between individuals creates a network of mutual trust, exchange of resources and support for each other. The networks based on biradari and VB relations within the organizations operate as group power and hold a strong influence on organizational activities. This group power is similar to group social capital. As defined by Oh, Chung, and Labianca (2004) "group social capital as the configuration of group's members' social relationships within the social structure of the group itself, as well as in the broader structure of the organization and outside of the organization to which the group belongs, through which necessary resources for the group can be accessed". We argue that it is the extension of Biradari and VB based relations within and outside of the group, creates strong group cohesion among group members resulting in the dominance of a particular social group within the organizations. This cohesion work as group social capital, significantly influence individuals' career and success outcomes at an individual (micro), group (meso), and society (macro) levels (Coleman, 1988; Portes, 1998; Putnam, 1993). Individuals receive multiple potential supports due to their involvement in multiple networks at the same time (Portes, 1998). It is evident that the healthier relations with group members as well as with other groups within the organization result in better access to needed resources, opportunities, to gain information, social support, political support, trust, and conclusively increased group effectiveness (Oh, Chung and Labianca, 2004). In our social context, the institution of Biradari, 
based on VB relations, works as the pooling of social capital in different organizational and political settings in Pakistan (Qadeer, 2006). Its significant function is to support and protect the group members. It helps in creating networks through processes of reciprocity among group members. This group social capital operates and maintained in multiple forms; trust, authority, reciprocity of obligations, and expectations. This capital is useful to achieve desired objectives that are difficult to attain in the absence of these relations. Burt (1997) and Nahapiet and Ghoshal (1998) highlighted that social capital makes it easier to have access to information which is unattainable to grasp alone, to receive information at the right time when it can be most beneficial, to receive and consider referrals from ones inner group to recruit/select their referred persons and maintenance of trust. Furthermore, these relations are also crucial to create extend familial linkages that are used a tool to control and to protect particular resources as well as for exerting power to secure other resources within the organizations (Ibrahim, 2009: Haider, 2014: Shabbir 2018; Nasir, Chaudary, Khan \& Hadi, 2015). These relations are also helpful to have access to information about the internal story of new job opportunities and other significant activities (Coleman, 1990: 300-21). It also makes it easier to introduce people with other groups from whom needed information can be obtained (Baker, 2000).

The structure and content of an individual's relation with their respective networks influence career success, access to information, promotions, and other resources (Adler \& Kwon, 2002; Seibert, Kraimer, and Liden (2001). These exchanges of services/gifts are considered as a medium to create, assert, support, or perpetuate particular relationships (Belk and Coon, 1983; Camerer, 1988). It has multiple implications and asserts a different impression at various levels. In Pakistan's cultural settings, individuals associated with particular Biradari/ Caste or Qaum also provide an important milieu to contact and approach a person with whom individuals do not have direct family ties or blood relations. These linkages and ties are significant in creating influence when employed in organizational settings. It plays an important role in organizational and political settings and individuals use Biradari association to approach and to have good contact with authorities (Lyon, 2002). The sentiments of association/belongingness provide more chances to integrate oneself in the Biraderi bonds within the organizations, thus, biraderi power is strengthened through 'exchange of mutual interests (Rauf, 2016). People approach higher authorities through involving individuals from authorities' networks specifically with whom strong VB relationships are maintained. This makes it difficult for the authorities to ignore the request (Saher, 2010). Thus, social practices under the cultural system of VB function like a glue stick. It unites and incorporates the different stratum of Biraderi relations in social and economic exchange and maintains a degree of certainty of mutual expectations (Nasir and Mielke 2015). The influence of this cultural practice is evident in bureaucracies, academic institutions, tax services, and police offices (Qadeer, 2006). However, this group social capital subverts the organizational rules and policies as people generally involve other influential channels/members rather than following the formal policies of the organizations.

There is always the significant influence of national/cultural values and beliefs on organizational HRM practices (Hofstede, 1980; Jackson, 2002; Arif \& Shabbir, 2019; Myloni, Harzing, \& Mirza, 2004). In Pakistan, the extensions of kinship relations have a sound impact on organizational cognitive and normative apparatuses, and greatly influence the managerial practices (Khilji, 2003). These cultural norms and values operate as a contextual imperative; constrain the organizational policies and HRM practices (Rhodes, Walsh \& Lok, 2008). The basic principle in VB relations is to always exchange something better for receiving a particular gift to continue a beneficial or effective relation. As highlighted by Blau that reciprocity serves as a social sanction for individuals. Individuals have to face repercussions if they are not able to provide expected obligations to associates and further, it can jeopardize the supply of other benefits. Thus, these exchange processes further create a strain toward imbalance and reciprocity. Hence, people are always interested to create a balance by providing at least comparable benefits to those from whom they receive the rewards (Blau, 1964:24). Similarly, in the case of relations based on Biraderi and VB, there is always internal bargaining of expectations with Biraderi members particularly when it is applied in organizational settings. The involvement of kinship ties and biraderi plays a crucial rule in the exchange of mutual interests and services in 
organizations of Pakistan (Qadeer, 2006: Shabbir et al, 2016: Rauf, 2016). Here gift exchanges or using influential members' references from the same Biradari group work as a mediator or intervening variable, which generally results in achieving desired objectives. The main cultural principles of arbitration, intervention, and reciprocation based on VB influence the organizational practices at different levels where social moralities of reciprocity are maintained along with organizational standards (Saher, 2010:2014). On the other hand, this exchange further produces feelings of gratitude, trust, and obligations among group members. In Pakistani culture, indebtedness/obligation is encouraged and taken as a cultural expression of loyalty (Lyon, 2002).

The loyalties to Biradari members, specifically in the organizational social networks, serve as the immense synchronization and domination of particular biraderi and their networks in Pakistani organizations. This loyalty is maintained and reflected in recruitments and other official processes by selecting the right person (Malik, 2014). Substantial researches confirm the strong role of informal association based on kinship, ethnic ties, and linguistic identities for creating social networks in regional and local economies, leather, textile industries, and other businesses (Qadeer, 1997; Ahmed \& Naeem, 2011; Shabbir 2015; Rauf, 2016). Saher and Mayhofer (2014) highlighted the role of a cultural constituent of Vartan Bhani in implementing Western HRM practices in the context of Pakistan. The research highlighted how VB through maintaining strong social networks influence recruitment, appraisal, selection, compensation, and promotion practices. Islam (2011) as cited by Malik (2014) states:

These kinship structures are so strong that they extend to towns and cities, penetrating the corporations, public bureaucracy, and the political system. The individual is closely integrated into these networks and they determine his/her status, mobility, and success. Family networks are the primary focus of loyalty. Their strength is reinforced by endogamous, cross-cousin marriages. These institutions impose a system of mutual obligations, which perpetuates patronage and nepotism in government and private enterprises (Islam, 2011: 323).

\section{Research Methodology}

To better understand how Biraderi and VB relations are practiced and experienced by the employees in their respective organizations, we used qualitative research methodology as it provides more detail and in-depth insight into the selected phenomenon under observation (Patton, 1990). Qualitative research primarily deals with discussions about the detailed examination of people's life experiences and events in their social context and interprets the meaning according to its socio-cultural settings (Beins, 2012; Hennink et al., 2011; Saleem et al., 2019; Neuman, 2000). Qualitative research is being used by researchers in organizational management to have a better understanding of the particular social phenomenon under observation (Ehigie \& Ehigie, 2005).

We have selected a diverse sample for our study consisted of two hospitals, two public sector universities, and two colleges of the capital city, Islamabad (five respondents from each organization). This study consists of thirty (30) in-depth interviews that were conducted from the respondents. Researchers' links and official contacts helped us to approach the respondents for their participation in this study. After respondents arranged for interviews, the interview guide was provided to them through emails and in some cases, through personal visits. Telephonic and face-to-face interviews were conducted in different phases depending on the availability of the respondents.

In the next phase, the obtained data were categorized into subsections. This categorization helped us to figure out similar responses under particular categories according to our research objectives. Then, the opinions of the respondents were carefully reviewed and summarized (Baxter, 1991). This categorization helped to figure out the responses. We selected and represented the most relevant comments/opinions of the respondents (content) that closely related to the central themes and reflected the main objectives of the study (Leedy \& Ormrod, 2001). We have organized the comments/opinions of the respondents under four major areas/themes (i.e. role of Biraderi and VB for creating networks, job selection, for access to information and other opportunities) The qualitative analysis was also beneficial to explore other significant patterns and themes from respondents' answers. Respondents' 
experiences, feelings, and perspectives provided us more insight about other significant patterns, practiced under biraderi and VB mechanism which are essential for obtaining successful results. For confidentiality purposes, we did not mention the names of employees, their designations, and institutions of the respondents in our discussion and analysis session.

\section{Results and Discussion}

The results highlight the perceptions of employees regarding the phenomenon of Biraderi relations and how Biraderi relations (group social capital) operate and maintained in official dealings in their respective organizations. Employees' perspectives provide more insight into the role of reciprocity using biraderi or fraternal relations for successful organizational favors and support.

Respondents' views highlight how reciprocity is manifested among biraderi members at various levels by giving gifts and favors. However, employees' professional status, and expected benefits to be achieved from in-group relations, determine the nature of reciprocal activities used for a successful exchange. At higher managerial levels, people try to approach related authorities by involving equally influential members of the same biraderi from other institutions. Sometimes, both parties set the issue through direct personal meetings. In some cases, along with personal meetings, the pressure is asserted by giving them extra social honor when related authorities are invited at different social and political gatherings as special guests, guest speakers. This activity provides a chance to introduce or promote a specific person for particular organizational favors. These practices play a considerable role to select or promote the same group members for specific favors Nguyen et al (2020). In some cases, friendships based associations within and outside of the organization are significant for achieving desirable favors. The responses highlight that how reciprocity, familial or familial ties play critical for offering more benefits to close members. According to one of the respondent

"No doubt network ties, specifically fraternity relations are important for having a job and other organizational supports in our organizational context. We have a procedure for the recruitment of employees, but we cannot ignore the role of the core management team. Their choices significantly affect recruitment procedures. Generally, they support biraderi, fraternity, or in-group circle ties".

Some respondents explained that

"One of my colleagues has secured a job through involving his uncle who is already working in the administration section. His uncle used the reference of a very close friend of the Head of Department and Dean. She told me after her selection that her uncle had invited the friend and the Dean for dinner two days before her interview".

"Yes, higher management can recruit or select individuals of their choices at any time without informing asking the related departments. These are high levels favors to their close kinship/friendship relations".

Results revealed that familial, extended familial relations are significant to create social networks which are essential elements for one's success in the organization. The main ingredients that work for the formation and further continuation of these networks are both familial and fraternity based ties. However, employees' ability to create and maintain relations with these networks determines one's success in these organizations. Our findings showed that employees have to rely on maintaining social networks that ultimately support them in upward mobility. According to the responses, employees prefer to make positive relations with immediate bosses and senior management and consider it highly beneficial for official matters. Results showed how making good relations with their immediate supervisors, bosses are beneficial for them. Familiar or biraderi ties provide them an extra edge to form and continue relations; also an edge over other employees who do not have strong ties with their immediate bosses/supervisors. Generally, employee/supervisor relations are initiated by involving friends, biraderi, or relatives from other departments of the organizations. These networks are formed through involving close relatives friends or relatives, who play an important role in maintaining good relations with immediate bosses, supervisors, and senior management. The relations are further strengthened through the exchange of services, favors, and gifts by employees and members of different departments within the organizations related through friends, relatives, or biraderi. 
Respondents highlighted how new social networks are built by frequently visiting each other, having informal social ties, and attending lunch and dinner together. Based on these activities, multiple relations are initiated among the employees that include: exchange of gifts, favors, or other official or unofficial services, mentoring relationships, and exchange of information. Furthermore, group relations are also maintained through providing services to each other by doing unofficial favors to bosses, performing unspecified tasks for them, sometimes gifts exchange on different occasions, and celebrating events like birthdays, particular achievements, and religious festivals, etc. These practices help the employees to secure privileges from their bosses in the process related to promotion and compensations.

As explained by our respondents:

"There is no doubt that we use our social circles and networks within and outside of the organizations for multiple purposes. We also provide favors to members of our social circle and this exchange of favors benefits us at different stages".

"As a faculty member, we have to maintain good interaction with our seniors, when we know their authority over our official issues. As in your case, I am directed by the head of the department to give an interview to you (he laughed). We have to make our seniors happy in every situation".

"Yes good and affective relations are important for us with our immediate bosses. My husband is working in the administration section of this organization. Mostly, I manage all the official tasks of my department, related to administration with the help of my husband. I know that on-time support of my husband helps me to maintain a very smooth relation with my boss".

Results highlight that employees also maintain good relations based on reciprocity of favors, gifts, and informal activities as more important to have linkages with people in power who hold a strong influence on employees' access to resources and upward mobility. It was also observed that employees who were maintaining good relations and providing every possible assistant to their immediate bosses and other people in power structure (from the same group) were more satisfied and enjoying the related benefits like political support, timely access to information, and office assistant for different matters. Therefore, both parties were equally benefiting the mutual reciprocity of services. Their linkages with the same group increase the flow of services for them at different levels.

"I was among those people who do not believe in networking for extra favors. But I have realized that we have to be dependent on some networks/channels for our official and routine matters in organizational settings. It's really difficult to handle official procedures without having connections with different departments". So we have to make more informal relations with senior colleagues for the effective utilization of our everyday tasks".

"It's not possible to manage our daily official activities without having good relations with different members working in different positions. I always remain in contact with them and also given them gifts on particular events, or invite them for lunch to celebrate the events. It's really important for us".

"My abilities and qualities are not enough to make things easy and smooth for me. We have to be active and clear in creating relations with other departments for our official dealings. This makes it possible for us to run our official matters smoothly.

Responses also highlighted that despite following specific criteria for selection of the candidate, it is always higher management who hold the power to select the person of their choice. This management work as a group of social capital that usually prefers to select or promote members of there in a group circle. Results revealed that securing a desired job, promotional process and other professional opportunities are difficult for employees without having any association with strong networks. Some respondents' perspectives highlight that achieving a particular job is all about approaching the right persons. According to responses, employees close to authorities remain aware of when information about new events or jobs is circulated among few members, they obtain boards' members list through involving friends or relatives within the originations. Then, board members are approached depending on links with any of the members. One of the respondents highlighted that "it's not like that all close references are used only for supporting their own personal/group interest, people 
who are eligible for a certain post and have excellent qualification and experience, also use network reference system by involving their close personal and professional relations during recruitment and selection processes. This practice is so strong in our society and people consider commitments based on familial/biradari and networks ties as more authentic and reliable than actually following the organizational rules and policies".

"Actually in most cases, people know that it's really helpful for them to approach higher authorities using social networks within and outside of organizations. Therefore, they rely heavily on using networks through the intervention of influential members and maintain good relations with their respective supervisors/immediate bosses".

"Yes, these relations do matters especially when we need a high-class reference for our professional matters. It is a fact that whenever I use my networks as a reference, I do not experience any difficulty in my official work".

However, respondents also expressed their views regarding the use of network relations and familial ties in organizational settings and why they are strongly practiced in organizations. One of the respondents explained that

"I think less job availability and economic insecurities have made the role of biraderi or related networking element very significant in our society. Despite having a regular mechanism for selection and promotions, people more rely on informal means based on connections to secure the job".

Respondents shared their views regarding group social capital and how they influence employees' organizational behavior within their respective organizations. We observed strong outside group biases among the members who did not consider themselves as a part of the dominant group within their respective departments or at administrative levels. These members considered ingroup relations as major constraints for other employees' career success as well as for organizational progress. According to responses, biraderi, or network associations working as group power within the organizations, promote and protect just in-group interests. One respondent explained that these power groups take organizational resources as their assets and technically distribute it within their own familial and social circle. This group power or group social capital discourages compatibility, merit-based selections, promotions, and motivations of other employees.

"These in-groups or networks control the organizational system. I know the members who have linkages with members in other organizational departments, do not face any delay in their official matters. They receive priority and sometimes tasks related to their department are done after official duties".

"My department is not promoting me as associate professor though I meet all the requirements. The fact is that my head of department wants to promote and protect his person for this post. He will be eligible for this post after four-month". The head of the department has full support from the registrar office so he will not ask for this post until his preferred person does not complete the required period".

However, most of the employees view these group relations or network ties as significant for their successful survival in a very complex and nepotistic organizational environment. They need to have good relations with the people of the same caste, regional, religious affiliations, and other groups as well within the organizations. In some cases, the association with strong and powerful groups also serves as a powerful symbol at the departmental level, provide privilege, promotions, and compensations to employees Shabbir (2019). It also saves employees from any kind of trouble in their professional and personal issues.

Results revealed that employees, who are engaged in reciprocal relations with members of the same groups as well as with other groups, receive more information regarding multiple organizational policies. Having links with multiple groups increases social capital and provides many benefits to employees such as more information medical facilities, various awards, packages, research grants, professional and educational opportunities, and major organizational events. Respondent also expressed their concerns about the negative impact of their less access to different educational and promotional opportunities within the organizations. According to them, this information is equally 
beneficial for all the employees and should be available. However, this information is not shared at broader levels within the organizations. Mostly, it is the people who have familial/biraderi ties within the power group structure who receive some information about these activities. As highlighted by our respondents

"Yes, group affiliation matters and provides multiple benefits specifically when you have affiliations in other departments for example in administration and finance sections. Most of the time, I remain unaware of many important educational and professional activities. My colleague is getting all the benefits (participation in research activities, seminars, and workshops) as her uncle is in the administration department and it's very easy for her to have access to different opportunities".

"We cannot ignore the familial or in-group factors in the selection or promotional processes. Despite meeting all the eligibility requirements for this post, I think it was my uncle's reference which provided strong support". He was the one who informed me about this job and asked to submit my documents".

"I think organizations, apparently follow organizational HRM policies, but take is just a formality as the selection is always pre-decided. It the management who always makes decisions according to their will and supports their personnel. So rules and regulations are created and manipulated according to the situations". We have examples of many cases in our organizations where senior management promotes their family members, friends.

"Having linkages with upper management is an indispensable requirement for a successful professional career in today's competitive environment".

Responses also revealed that higher administration in respective organizations is divided into different groups, hold organizational resources, and use in-group members from lower hierarchies to maintain their dominance. It is not enough to have a particular link or other fraternity association to become a part of power networks at higher levels. At this level, in some cases, in-group ties are maintained through the exchange of high-level favors (official and unofficial), that provide equal benefits to both parties. One respondent said: "A very close relative of assistant academic is hired in finance department due to high favors given to our administration by his (assistant academic) elder brother in a high court case.

\section{Conclusions}

Based on the main assumptions of social exchange theorists, this paper highlights and discloses how the cultural institutions of Biraderi and Vartan Bhanji are used to establish in-group relations and further this group cohesion function as group social capital in organizations. The main objective of this paper is to highlight how employees use different familial or fraternity relations for diverse purposes that successfully influence their relationships within the organizations. Results revealed that affiliations with particular groups based on biraderi/fraternity relations serves as a basic marker of group cohesion/power and increase the probability of success for employees in multiple official affairs. The employee uses Biradari affiliations (either recognition or participation) for the effective accomplishment of personal benefits and favors. These affiliations are developed at different hierarchal levels within the organizations using networks of biraderi/fraternity relations. For effective utilization of group affiliations within the organizations, people exchange gifts that function symbolically for more consideration of Biraderi and VB ties. These mechanisms are utilized as an effective strategy to create a network of relationships to secure personal and group interests. As our results signify that higher authorities prefer to promote, support, and protect individuals from their social group at different organizational hierarchies. Similarly, the strategy of VB also work to assert personal pressure on individuals to make them obliged through giving them favors or other benefits

Results revealed that dominant networks based on personal, familial relations operate as group social capital within the organizations. The group social capital is significant for facilitating employees in their official dealings and upward mobility. However, it is also considered as a constraining factor for employees who do not actively become part of any network within the organizations. Results also highlighted that the dominant social group can utilize organizational resources, can easily manipulate 
or make new policies depending on the circumstances. This practice is reflected in implementing organizational HRM practices.

Employees recognize the importance of having connections with power groups within organizations that facilitate them in the utilization of their multiple organizational interests. However, members' position and interaction in these power group structures is vital to secure and control benefits and in some situations. Employees with strong ties and larger networks experience a smooth flow of resources within their social groups such as support in promotions, access to information, using influential references, and political support that ultimately increases the specific group dominance within the organizations (i.e. biraderi or fraternity-based networks in this case).

In this paper, we have tried to measure the nature and basis of social ties for in-group relations that ultimately lead to the formation of group social capital by having linkages with diverse networks. Furthermore, these relations become a great source for transforming resources and social/political support to its particular members. However, despite having in-group relations, employees professional status, and social positioning within the social structure are significant to determine how reciprocity is perceived among group members. People also use excessive favors as a symbolic means of control and to assert and maintain group social pressure within the organizations. The relations under these practices are of great significant specifically from a psychological perspective as it generates feelings of obligations and indebtedness. Particularly, when individuals who receive certain favor, not able to provide at least comparable benefits to those from whom they receive the reward/gift. Therefore, we suggest that future research should consider the elements of hierarchies of organizational positions and actual social positioning of employees in observing the practices of these relations. Particularly, how reciprocity is used as symbolic violence through excessive favors and how it influences employees' social and organizational relationships.

Author Contributions: Ms. Tasmia Matloob has conducted the interviews, methodology, and data analysis parts, while Mr. Malik Shahzad worked on the introduction and literature parts.

Funding: This research received no external funding.

Acknowledgments: The authors are grateful to the anonymous referees of the journal for their extremely useful suggestions to improve the quality of the paper.

Conflicts of Interest: The authors declare no conflict of interest.

\section{References}

Ahmed, M. (2006). Biraderi role in interest articulation in Pakistan. Journal of Social Sciences, 2 (1), 112

Ahmad, M. \& Naseem, F. (2011). The social system influences the political system: A comparative study of subcontinent. Berkeley Journal of Social Sciences, 1 (1), 72-80.

Akhtar, N. \& Mushtaq, S. (2014). The dynastic elites and its recruitment in political process of Pakistan. Berkeley Journal of Social Sciences, 4 (1), 1-18.

Arif, A., \& Shabbir, M. S. (2019). A common currency for Islamic countries: is it viable? Transnational Corporations Review, 11(3), 222-234.

Asia Pacific Human Development Report. (2010). Power, voice, and rights: A turning point for gender equality in Asia and the pacific.

Awan, M.A. (2016). Political participation of women in Pakistan: historical and political dynamics shaping the structure of politics for women. Global Islamic.

Bari, F. (2005). Women's political participation: Issues and Challenges. Draft paper, division for the advancement of women.

Bari, F. (2015). Bridging the fault lines? Rethinking the gender quota approach in Pakistan. Publication Series: Reviewing Gender Quotas in Afghanistan and Pakistan.

Ballington, J. \& Karam, A. (2005). Women in parliament: beyond numbers. International Institute for Democracy and Electoral Assistance: Sweden. 34-39.

Bari, (2017). Women parliamentarians: Challenging the frontiers of politics in Pakistan. Gender, Technology, and Development. 14 (3), 363-384. 
Basu, A. (2005). Women, political parties, and social movements in South Asia. Governing women: Women's political effectiveness in contexts of democratization and governance reform,94-97.

Ballington, J. \& Matland, R.E. (2004). Political parties and special measures: enhancing women's participation in electoral processes, 19-22.

Bjarnegard, E. \& Kenny, M. (2016). Comparing candidate selection: A feminist institutionalist approach. Government and Opposition, 51, (3), 370-392. DOI: 10.1017/gov.2016.4

Butt, K.M, \& Victor, T. (2014). Women empowerment by local representation: a case study of Lahore, 12-14.

Castillejo, C. (2013). Gender and state-building. Routledge Handbook of International State building, 33.

Candland, C. (2007). Workers' Organizations in Pakistan: Why no Role in Formal Politics? Critical Asian Studies, 39 (1), 35-57.

Derichs, C., \& Thompson, M.R. (2003). Dynastien und politische Führerinnen in Asien'.

Dahlerup, D. (2005). Enhancing women's political participation: legislative recruitment and electoral systems. In Women in Parliament: Beyond Numbers. A Revised Edition, 93-111.

Dahlerup, D. (2006). Electoral quotas: Frequency and Effectiveness. In Women, Quotas, and Politics, 275-292.

Dahlerup, D. \& Freidenvall, L. (2005). Quotas as a 'fast track' to equal representation for women - Why Scandinavia is no longer the model. International Feminist Journal of Politics, 7 (1), 26-48

Dutoya, V. (2013). From women's quota to “women's politics. The impact of gender quotas on political representations and practices in the Pakistani national parliament. Femina Politica, Politica, 2,17-34.

Fazal, H. \& Tariq, S. (2016). Socio-economic implications and participation of women in Pakistani politics. Pakistan Journal of Social Sciences, 36 (2), 947-957.

Fleschenberg, A. (2008). Asia's women politicians at the top: roaring tigresses or tame kittens? In Iwanaga, K. (Eds.), Women's political participation and representation in Asia: obstacles and challenges. (pp. 33-35).

Fleschenberg, A. (2013). Benazir Bhutto: her people's sister? A contextual analysis of female Islamic governance. In Derichs, C. \& Thompson, M. (Eds.), Dynasties and female political leaders in Asia. gender, power, and pedigree. 69.

Gender Review of Political Framework for Women Political Participation. (2010). Institutional strengthening of NCSW Support to Implement of GRAPs, National Commission on the Status of Women, Islamabad.

Gopalan, J. (2012). Women in politics in South Asia. Background Paper Series, Prajnya Resource Centre on Women in Politics and Policy.

Hinojosa, M. (2005). Sex and the cities: candidate selection and women's representation in municipal politics in Chile and Mexico. Doctoral dissertation, Harvard University, Massachusetts.

International Institute for Democracy and Electoral Assistance. (2007). Political parties in South Asia: The challenge of change. South Asian Regional Report Based on research and Dialogue with political parties.

Jabeen, M. \& Jadoon, M.Z.I. (2009). Gender and local governance in Pakistan: Representative vs. participation. International NGO Journal. 4, (5), 264-276.

Jahan, R. (1987). Women in South Asia. Third World Quarterly, 9 (3), 848-870.

Jalazai, F \& Krook, M.L. (2010). Beyond Hillary and Benazir; women's political leadership worldwide. International Political Science Review, 31(1), 5-23.

Krook, M.L. (2007). Candidate gender quotas: A framework for analysis. European Journal of Political Research, 46. 367-394.

Krook, M. L. (2009). Quotas for Women in Politics: Gender and Candidate Selection Reform Worldwide, New York: Oxford University Press.

Lyon, S. (2002). Power and patronage in Pakistan.", Ph.D. Dissertation, University of Kent, Canterbury.

Matland, R. E. \& Montgomery, K.A. (2003). Women's access to political power in post-communist Europe.

Matland, R. (2005). Women's political participation: Legislative recruitment and electoral systems. In Ballington, J. \& Karam, A. (Eds.), Women in parliament: beyond numbers, 93-111.

Macaulay, F. (2006). Gender politics in Brazil and Chile: the role of parties in the nation and local policymaking. 103-106.

Majid, F.B., Kabir, P., \& Kabir, R. (2008). Breaking the barriers: claiming women's space in politics in South Asia. Mumtaz, K. (2005). Women's representation, effectiveness, and leadership in South Asia.

Nguyen, V.K., Shabbir, M. S., Sail, M.S., \& Thuy, T. H. (2020). Does the informal economy impede economic growth? Evidence from an emerging economy. Journal of Sustainable Finance E Investment. 
Norris, P. (1997). Introduction: Theories of recruitment and conclusions: comparing passages to power. In Norris, P. (Eds.), Passages to Power: Legislative Recruitment in advanced democracies,1-14.

Norris, P. \& Lovenduski, J. (1995). Political recruitment: gender, race, and class in the British parliament. Cambridge University Press.

Norris, P., \& Inglehart, R. (2000). Cultural barriers to women's leadership: A worldwide comparison.

Pandey, A. (2005). South Asia: politics of South Asia: Women's political participation, 17.

Pitre, S. (2003). Women's struggle for legislative power: The role of political parties. Atlantis, 27 (2), 102-109.

Saddiqui, U. A. (2014). Hierarchy of women political participation and incommensurability between women representation and empowerment in South Asia: Pakistan in perspective. 12-14.

Saher, N. \& Mayrhofer, W. (2013)., The role of Vartan bhanji in implementing HRM practices in Pakistan. The International Journal of Human Resource Management, 25 (2), 1881-1903.

Saleem, H., Khan, M. B., \& Shabbir, M. S. (2019). The role of financial development, energy demand, and technological change in environmental sustainability agenda: evidence from selected Asian countries. Environmental Science and Pollution Research, 1-15.

Sharma, P. (2014). The oligarchic patriarchal political culture of women participation in South Asia: with special reference to India, Bangladesh, Pakistan.

Shaheed, F. (2002). Imagined citizenship: women, state, and politics in Pakistan.

Shaheed, F. (2010). Great revolts and small rebellions: citizenship and the social dimension of movement building imagined.

Shabbir, M. (2015). Innovation and competitiveness lead to industrial trade. Available at SSRN 2659847.

Shabbir, M. S. (2019). Informal shariah pawnshop in the traditional markets of Surakarta. Journal of Islamic Marketing.

Shabbir, M. S., Ghazi, M. S., \& Mehmood, A. R. (2016). Impact of social media applications on small business entrepreneurs. Arabian Journal of Business and Management Review, 6(3), 203-05.

Shabbir, M. S. (2019). Nexus between customer preference and operation of conventional banks Islamic windows in Pakistan. Journal of Islamic Marketing.

Shabbir, M. S. (2018). Classification and prioritization of waqf land: a Selangor case. International Journal of Islamic and Middle Eastern Finance and Management, 11(1), 40-58.

Syed, J., Ali., F., \& Winstanley, D. (2005). In pursuit of modesty: contextual emotional labor and the dilemma for working women in Islamic societies. International Journal of Work Organization and Emotion, 1 (2), 150-167.

True, J., Niner, S., Parashar, S. \& George, N. (2012). Women's political participation in Asia and the pacific.

Vivian Roza, M.A. (2010). Gatekeepers to power: party-level influences on women's political participation in Latin America.

Zakaria, R. (2016,). The thorny question of quotas. Daily Dawn.

(C) 2020 by the authors. This article is an open-access article distributed under the terms and conditions of the Creative Commons Attribution (CC BY) license (http://creativecommons.org/licenses/by/4.0/). 